\title{
Seizure Freedom Reduces Illness Intrusiveness and Improves Quality of Life in Epilepsy
}

\author{
Sonia Poochikian-Sarkissian, Souraya Sidani, Richard Wennberg, \\ Gerald M. Devins
}

\begin{abstract}
Background: Chronic illnesses are associated with multiple stressors that compromise quality of life (QOL). Implicit in many of these stressors is the concept of illness intrusiveness: the disruption of lifestyles, activities, and interests due to the constraints imposed by chronic disease and its treatment. The purpose of this study was to examine illness intrusiveness and QOL in epilepsy in patients with different levels of seizure control. Methods: Cross-sectional data were obtained and compared between two groups of patients categorized by presence of seizures: seizure freedom or continued seizures $(\mathrm{N}=145)$. Standard instruments measured the following variables: illness intrusiveness, perceived personal control, subjective well-being, and disease specific QOL. Results: Illness intrusiveness varied inversely and significantly with seizure control. Complete seizure freedom, whether achieved by pharmacological or surgical treatment, was associated with the lowest levels of illness intrusiveness. Seizure freedom was also associated with increased perceived control, positive affect, self-esteem and QOL in epilepsy. Conclusions: The most robust benefits of decreased illness intrusiveness in epilepsy occur when treatment leads to complete seizure control. Therefore every effort should be made by health care providers to achieve seizure freedom to reduce illness intrusiveness and improve QOL in epilepsy.
\end{abstract}

RÉSUMÉ: La disparition des crises convulsives diminue l'effet de perturbation de la maladie et améliore la qualité de vie dans l'épilepsie. Contexte : Les maladies chroniques sont associées à de multiples facteurs de stress qui compromettent la qualité de vie (QV). Le concept d'effet de perturbation de la maladie est implicite dans plusieurs de ces facteurs de stress : la perturbation du mode de vie, des activités et des intérêts à cause des contraintes imposées par une maladie chronique et son traitement. Le but de cette étude était d'examiner l'effet de perturbation de la maladie et la QV dans l'épilepsie chez des patients présentant différents niveaux de contrôle des crises. Méthodes : Nous avons recueilli des données transversales et nous avons séparé les patients en deux groupes, selon la présence ou l'absence de crises $(\mathrm{N}=145)$. Les variables suivantes ont été mesurées au moyen d'instruments standards : l'effet de perturbation dû à la maladie, le contrôle personnel perçu par le patient, son bien-être et sa QV spécifique de la maladie. Résultats : L'effet de perturbation de la maladie variait inversement et significativement selon le contrôle des crises. La disparition des crises, soit par un traitement pharmacologique ou chirurgical, était associée aux niveaux les plus bas d'effet de perturbation dû à la maladie. La disparition des crises était également associée à une augmentation du contrôle perçu, l'affect positif, l'estime de soi et la QV dans l'épilepsie. Conclusions : Les bénéfices les plus robustes de la diminution de l'effet de perturbation dû à la maladie dans l'épilepsie se retrouvent quand le traitement assure le contrôle complet des crises. Les professionnels de la santé devraient donc viser à faire disparaitre les crises afin de diminuer l'effet de perturbation dû à la maladie et d'améliorer la QV dans l'épilepsie.

Can. J. Neurol. Sci. 2008; 35: 280-286

Epilepsy is a chronic disorder, characterized by unpredictable, uncontrolled seizures that interfere with lifestyles, activities, and interests. The condition introduces a number of psychosocial challenges and adaptive demands, threatening quality of life (QOL). Research investigating the impact of epilepsy on QOL has traditionally emphasized disease factors (e.g., seizure frequency and severity), treatment effectiveness (e.g., as produced by pharmacological agents or surgery), adverse effects of anti-epileptic drugs (AEDs), or complications of surgical treatment (e.g., for intractable seizures). In addition to factors directly attributable to the disease and/or its treatments, epilepsy introduces psychological and social stressors that affect health-related quality of life (HRQOL). Epilepsy exerts a substantial impact on employment, social life, mood and sense

From the Divisions of Neurology, Krembil Neuroscience Program (SPS, RW), Behavioural Sciences and Health (GMD) and School of Nursing (SPS, SS), University of Toronto, University Health Network, Toronto Western Hospital, Toronto, ON, Canada.

Received April 27, 2006. Final Revisions Submitted February 5, 2008 Reprint requests to: Sonia Poochikian-Sarkissian, University of Toronto, University Health Network, Toronto Western Hospital, 399 Bathurst St., MP 5-311, Toronto, ON, M5T 2S8, Canada. 
of well-being. ${ }^{1,2}$ Some studies have highlighted stigmatization, a sense of loss of control, fear of seizures, social isolation and emotional difficulties that pose adaptive challenges. ${ }^{3,4}$ One study found significant correlations between adverse effects of AEDs and HRQOL, depression and HRQOL, and no correlation between seizure frequency and HRQOL. ${ }^{5}$ However, the most consistently described determinant of self-reported QOL appears to be the degree of seizure control achieved. ${ }^{5-9}$

Epilepsy clinicians and researchers have long recognized that seizure frequency compromises their patients' well-being. Those who are seizure free with pharmacological treatment report HRQOL levels similar to that observed in the general (physically healthy) population. ${ }^{9}$ Studies of pharmacologically treated epilepsy consistently identify benefits in HRQOL, with the most substantial effects evident when patients achieve complete seizure freedom. More limited HRQOL benefits arise when patients achieve reduced seizure frequency, but not complete seizure freedom. ${ }^{10,11}$

Epilepsy surgery often results in significant reductions in seizure frequency. For many patients, anterior temporal lobectomy, the most common form of resective surgery, results in complete seizure freedom or limits occurrences to rare, isolated incidents. ${ }^{12,13}$ Studies evaluating the effectiveness of temporal lobectomy in patients with medically refractory seizures have, in general, demonstrated improved psychological functioning due to substantially reduced seizure frequency or complete seizure freedom. .,7,14-19 $^{-1}$

A recent study $^{20}$ identified the QOL domains that are important to persons with epilepsy treated with pharmacological agents with the aim of assessing the perceived impact of epilepsy on QOL. These questions were addressed using an open-ended survey approach among a community-based sample of 46 adults with epilepsy. The investigators inferred a multi-domain structure of QOL based on qualitative data analysis. Epilepsy was construed as having both a direct and an indirect impact on QOL by affecting QOL domains and by influencing factors that contributed to QOL. Frequently identified contributors (i.e., factors that preserve or enhance QOL) included social and family support, religion or spirituality, leisure, mental health, and employment. Addressing the detractors (i.e., factors that compromise QOL), such as psychological distress, worry of seizure occurrence, transportation limitations, and stigma, the investigators speculated that a number of factors directly associated with epilepsy affect the above-mentioned contributors. Detractors may directly influence one's willingness and/or ability to pursue employment or leisure activities, for example, and may influence social and family support. This approach is consistent with the Illness Intrusiveness theoretical framework..$^{21}$

The concept of illness intrusiveness relates to illness-induced disruptions to valued activities and interests that compromise QOL in chronic conditions, such as epilepsy. Illness intrusiveness has been conceptualized as a link between the circumstances of a disease and its treatment, on one hand, and subjective well-being, or QOL, on the other. ${ }^{22-25}$ The framework maintains that QOL is compromised to the extent that disease factors, such as seizure frequency, and treatment factors, such as pharmacological or surgical treatment for epilepsy, interfere with valued activities and interests, reducing the availability of rewarding experiences and personal control. ${ }^{22}$ Evidence from diverse chronic disabling conditions has substantiated the illness intrusiveness framework in end-stage renal disease, ${ }^{26,27}$ multiple sclerosis, ${ }^{23}$ rheumatoid arthritis, ${ }^{23}$ breast cancer, ${ }^{28}$ systemic lupus erythematosus ${ }^{25}$ psychiatric conditions, ${ }^{29,30}$ solid organ transplant recipients, ${ }^{31,32}$ sleep disorders ${ }^{33}$ and epilepsy. ${ }^{34}$

Gilliam and colleagues ${ }^{35}$ showed that mood status and reported adverse medication side effects were significantly improved in patients following temporal lobe resection in epilepsy as compared to patients awaiting surgery. Lehrner et $\mathrm{al}^{36}$ studied 56 consecutive patients with mesial temporal lobe epilepsy and assessed HRQOL and depression. These investigators found that depression was significantly and inversely correlated with HRQOL measures, even after controlling for seizure frequency, seizure severity and other psychosocial variables. However, the cross-sectional study of Lehrner and colleagues contained no seizure-free patients, and thus was unable to address the influence of seizure freedom on mood and HRQOL.

In this study, we examine the influence of complete versus incomplete seizure control on illness intrusiveness and HRQOL.

\section{Methods}

The data for this analysis were obtained as part of a larger project investigating the theory of illness intrusiveness in epilepsy. ${ }^{34}$ For the purposes of this study, a naturalistic crosssectional design was used to compare patients with different levels of seizure control, based on self-reported seizure frequency in the past year, categorized into two groups: seizurefree and continued seizures. This two-way categorization was chosen to be consistent with seizure frequency classifications previously reported in the relevant literature, where the most obvious differences found in QOL were between seizure-free patients and those who continued to have seizures. This categorization also parallels one of the most important comparative subclassifications of the Engel classification scheme ${ }^{12}$ for seizure control after epilepsy surgery, where Class I = seizure free, and Classes II - IV represent progressively poorer control of seizures after surgical treatment. As part of the larger project, we also sub-classified the continued seizures group into patients with (a) $<3$ seizures per year (equivalent to Class II in the Engel post-surgical scale), (b) 3 seizures per year to 5 seizures per month, and (c) $\geq 6$ seizures per month, but concentrate in this study on the two-way grouping as potentially most relevant to QOL. Participants who were treated either pharmacologically or surgically were recruited from the Epilepsy Program at the Toronto Western Hospital, University Health Network, an academic tertiary care centre. Study sample size was estimated using the SPSS ${ }^{37}$ Sample Power program. Relevant considerations included two groups categorized by presence of seizure, alpha of 0.05 , power of 0.80 , and a medium effect size for the Illness Intrusiveness Rating Scale (SD= 17.3). ${ }^{38}$ Consecutive patients who satisfied the study inclusion and exclusion criteria were enrolled at the time of their followup appointments in the epilepsy clinic. All eligible patients $(\mathrm{N}=146)$ consented to participate in the study, yielding a response rate of $100 \%$. One patient was excluded from the study following the diagnosis of nonepileptic seizures, resulting in a total sample of 145 patients, divided into two groups. Group one 
included seizure-free patients, and the second group included patients who continued to have seizures. Of these, $92(63.4 \%)$ were pharmacologically treated and $53(36.6 \%)$ had been treated surgically for medically refractory epilepsy. The pharmacologically treated patients included patients whose seizures were satisfactorily controlled with AEDs, patients with medically refractory epilepsy awaiting testing to determine surgical candidacy, and patients who were already determined not to be surgical candidates based on epilepsy syndrome (e.g., primary generalized epilepsy; symptomatic generalized epilepsy and multi-focal epilepsies). The surgically treated patients had previously undergone resective surgery as a treatment for medically refractory epilepsy. For the purposes of this study, the four characteristics (seizure frequency, employment status, current number of AEDs, and side effects of AEDs) that correlated with the concepts of interest (i.e., illness intrusiveness and HRQOL) were retained as covariates (further discussed in Covariate Identification section).

\section{Procedure}

Following approval by the institutional Research Ethics Board, the neurologist (RW) identified consecutive eligible patients, who satisfied the study inclusion and exclusion criteria. The investigator subsequently contacted the patients, explained the study and administered the questionnaires after obtaining informed consent. Participants completed the questionnaires in a private room within the clinic.

\section{Inclusion and exclusion criteria}

Patients with epilepsy were eligible for inclusion in the study if they were 18 years-of-age or older and able to communicate in the English language. Pharmacologically treated patients were those whose treatment was stabilized no less than one year prior to participation in the study. All surgical patients who participated in this study represented individuals who had undergone surgery at least one year before completing the study materials. Prospective participants were excluded if they had secondary medical diagnoses that might contribute to illness intrusiveness, such as cancer, diabetes, heart disease or hypertension.

\section{Materials/Measures AND Methods}

The self-report questionnaires contained standard instruments measuring the variables of interest: illness intrusiveness, perceived personal control, subjective well-being, and disease specific (epilepsy) HRQOL.

Illness Intrusiveness was measured by the Illness Intrusiveness Ratings Scale (IIRS). ${ }^{21}$ The IIRS is a 13 -item selfreport instrument in which individuals rate the extent to which their illness and/or its treatment interfere with each of 13 life domains relevant to QOL, ${ }^{39}$ such as health, work, personal life and social life. The IIRS uses a 7-point rating scale, ranging from $1=$ Not Very Much to $7=$ Very Much, to measure the degree of lifestyle interference attributable to disease and/or treatment factors.

Personal Control was measured by the Control Ratings Scale. ${ }^{21}$ This questionnaire entails 13 items asking patients how much control they have over the same 13 life domains covered in the IIRS.
Two complimentary approaches were used to measure QOL: subjective well-being and disease specific (epilepsy) healthrelated quality of life $(H R Q O L)$. Four instruments were administered to assess complementary dimensions of subjective well-being (including psychological well-being and emotional distress) because no single instrument provides a comprehensive assessment of these diverse, subtly distinctive facets of QOL. ${ }^{40}$ Psychological well-being was assessed using the following three widely established self-report instruments: Affect Balance Scale $^{41}$ (ABS), Atkinson Life Happiness Rating Scale, ${ }^{42}$ and Rosenberg Self-Esteem Inventory. ${ }^{43}$

The ABS is a well-validated measure of psychological wellbeing that has been used extensively in physically healthy and various illness populations. ${ }^{41}$ It includes two subscales measuring positive (Positive Affect Subscale, PAS) and negative mood (Negative Affect Subscale, NAS). Each subscale consists of five binary (Yes/No) items to indicate the mood state during the preceding week.

The Atkinson Life Happiness Rating Scale is a single-item assessing overall happiness in life. It consists of an 11-point numeric rating scale ranging from 1 (very unhappy) through 6 (an even mixture of unhappiness and happiness) to 11 (very happy). The instrument's psychometric adequacy has been established in previous investigations. 23,26,27

Self-Esteem was measured by the Rosenberg Self-Esteem Inventory, a self-administered scale that asks respondents whether they agree or disagree with ten statements about selfworth. The range of possible scores is from 10 to 40, with higher scores indicating higher levels of self-esteem. Strong evidence supports its reliability and validity. ${ }^{44}$ The scale has an internal consistency reliability of 0.92 and test-retest correlations of 0.85 and 0.88 over two weeks.

Emotional distress was assessed by the Center for Epidemiologic Studies Depression (CES-D) Scale. ${ }^{45}$ It is a 20item self-administered questionnaire designed to measure depressive symptomatology in the general (i.e., non-psychiatric) population, addressing the frequency with which one has experienced depressive symptoms during the preceding week. It uses a 4-point forced-choice response format, ranging from 0 , "rarely or none of the time, to 3 , "most or all of the time. It has high internal consistency reliability (Cronbach's alpha 0.84 to 0.90). All of these instruments have been widely used in physically healthy and ill populations and their psychometric adequacy has been established in previous investigations.

Health-Related Quality of Life was evaluated by the Quality of Life in Epilepsy (QOLIE) Scale, ${ }^{46}$ a 10 -item questionnaire (QOLIE-10) for screening patients with epilepsy about the impact of the epilepsy on their lives. It entails a subset of items from the more extensive QOLIE-89. ${ }^{47}$ Total QOLIE-10 scores range from 5 to 50 . High scores indicate poor QOL. The QOLIE10 was selected as a measure of HRQOL because it is brief, simple, and can be completed quickly by patients.

\section{RESULTS}

\section{Demographic characteristics}

Demographic characteristics for the study sample are presented in Table 1. The results of group comparisons indicated differences only in education level attained. A larger percentage of patients in the continued seizures group had attended college 
Table 1: Patient demographic characteristics by seizure-free and continued seizure groups

\begin{tabular}{|c|c|c|}
\hline $\begin{array}{l}\text { Demographic } \\
\text { Characteristic }\end{array}$ & $\begin{array}{c}\text { Seizure-free } \\
(n=48)(33.1 \%)\end{array}$ & $\begin{array}{c}\text { Continued seizures } \\
(\mathrm{n}=97)(66.9 \%)\end{array}$ \\
\hline Age in years $(+/-\mathrm{SD})^{\mathrm{a}}$ & $39.15+/-11.72$ & $37.7+/-11.83$ \\
\hline Gender $^{b}$ & $\begin{array}{c}\text { Male }-37.5 \% \\
\text { Female }-62.5 \%\end{array}$ & $\begin{array}{c}\text { Male }-44.3 \% \\
\text { Female }-55.7 \%\end{array}$ \\
\hline Marital Status $^{c}$ & $\begin{array}{c}\text { Single }-37.5 \% \\
\text { Married }-54.2 \% \\
\text { Separated }-8.3 \% \\
\text { Widowed }-0.0 \%\end{array}$ & $\begin{array}{c}\text { Single }-48.5 \% \\
\text { Married }-39.2 \% \\
\text { Separated }-10.3 \% \\
\text { Widowed }-2.0 \%\end{array}$ \\
\hline Employment Status $^{\mathrm{d}}$ & $\begin{array}{c}\text { Unemployed / Retired }-31.25 \% \\
\text { Part-time }-16.7 \% \\
\text { Full-time }-52.05 \%\end{array}$ & $\begin{array}{c}\text { Unemployed / Retired }-59.8 \% \\
\text { Part-time }-15.5 \% \\
\text { Full-time }-24.7 \%\end{array}$ \\
\hline Education $^{e}$ & $\begin{array}{c}\text { High school or less }-35.4 \% \\
\text { College / University }-47.9 \% \\
\text { Technical training }-16.7 \%\end{array}$ & $\begin{array}{c}\text { High school or less }-37.1 \% \\
\text { College / University }-55.6 \% \\
\text { Technical training }-7.3 \%\end{array}$ \\
\hline
\end{tabular}

${ }^{\mathrm{a}} \mathrm{F}(2,142)=1.31, \mathrm{~ns} ;{ }^{\mathrm{b}} \mathrm{X}^{2}(1)=2.67, \mathrm{~ns} ;{ }^{\mathrm{c}} \mathrm{X}^{2}(6)=6.21, \mathrm{~ns} ;{ }^{\mathrm{d}} \mathrm{X}^{2}(2)=3.20$, $\mathrm{ns} ;{ }^{\mathrm{e}} \mathrm{X}^{2}(4)=10.63, \mathrm{p}<0.05$. the lone variable retained as a covariate for analyses involving affect balance, self-esteem, happiness and depression. Analysis of covariance (ANCOVA) compared the two patient groups based on presence vs. absence of seizures.

\section{Seizure control and illness intrusiveness}

Patients in the two seizure group categories (seizure-free and continued seizures) differed significantly in illness intrusiveness $(\mathrm{t}-\mathrm{value}=5.30, \mathrm{df}=143, \mathrm{p}<0.01)($ Table 3$)$. Those who were seizure-free reported lower levels of illness intrusiveness than those with continued seizures.

\section{Seizure control and psychosocial outcomes}

The same analytic strategy (ANCOVA) was employed for each of the psychosocial outcome variables, including personal control, depression, happiness, self-esteem, positive and negative affect and QOLIE. Table 3 reports the adjusted means for each of the QOL variables. All psychosocial outcomes differed significantly between the seizure-free and continued seizure groups. Seizure freedom, whether achieved with

Table 2: Clinical characteristics by seizure-free and continued seizure groups

\begin{tabular}{|c|c|c|}
\hline $\begin{array}{c}\text { Clinical } \\
\text { Characteristic }\end{array}$ & $\begin{array}{c}\text { Seizure-free } \\
(n=48)\end{array}$ & $\begin{array}{c}\text { Continued seizures } \\
(\mathrm{n}=97)\end{array}$ \\
\hline $\begin{array}{l}\text { Mean age at diagnosis in years } \\
(+/ \text { SD })^{\mathrm{a}}\end{array}$ & $18.56+/-13.1$ & $17.86+/-13.35$ \\
\hline $\begin{array}{l}\text { Mean duration of seizures in years } \\
(+/ \text { SD })^{b}\end{array}$ & $22.60+/-11.60$ & $19.78+/-14.36$ \\
\hline $\begin{array}{l}\text { Number of failed anti-seizure } \\
\text { medications }(+/-\mathrm{SD})^{\mathrm{c}}\end{array}$ & $3.5+/-2.21$ & $3.29+/-2.53$ \\
\hline Number of side effects (+/-SD) ${ }^{d}$ & $3.1+/-1.25$ & $3.23+/-0.9$ \\
\hline 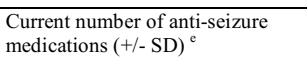 & $1.39+/-0.89$ & $1.86+/-0.8$ \\
\hline
\end{tabular}

${ }^{\mathrm{a}} \mathrm{F}(2,142)=2.44, \mathrm{p}=0.091 ;{ }^{\mathrm{b}} \mathrm{F}(2,142)=6.5, \mathrm{p}<0.005 ;{ }^{\mathrm{c}} \mathrm{F}(2,142)=11.08$, $\mathrm{p}<0.001 ;{ }^{\mathrm{d}} \mathrm{F}(2,142)=0.069, \mathrm{~ns} ;{ }^{\mathrm{e}} \mathrm{F}(2,142)=4.98, \mathrm{p}<0.01$

pharmacological or surgical treatment, was associated with the lowest illness intrusiveness and depression scores, and with increased control, happiness, self-esteem, positive affect and QOLIE scores. The seizure-free group reported lower levels of depression and negative affect, and higher levels of perceived control over diverse domains of life, higher levels of happiness, self-esteem, positive affect and QOLIE (note that increasing scores on the QOLIE-10 scale indicate decreasing QOL).

\section{DisCUSSION}

Epilepsy is a chronic disorder, characterized by unpredictable, uncontrolled seizures and physiological changes, 
Table 3: Illness intrusiveness and psychosocial outcome variables: comparison of seizure-free and continued seizure groups

\begin{tabular}{|c|c|c|c|}
\hline Variable & $\begin{array}{c}\text { Seizure-free } \\
\text { Mean }(+/- \text { SD) } \\
\quad(n=48)\end{array}$ & $\begin{array}{c}\text { Continued Seizures } \\
\text { Mean (+/- SD) } \\
(\mathbf{n}=97)\end{array}$ & $t$-value $(d f=143)$ \\
\hline Illness Intrusiveness & $27.27+/-17.30$ & $44.4+/-18.38$ & $5.30 * *$ \\
\hline $\begin{array}{l}\text { Perceived Personal } \\
\text { Control }\end{array}$ & $84.06+/-14.04$ & $65.24+/-15.79$ & $6.99 * *$ \\
\hline CES-D & $10.52+/-9.40$ & $19.36+/-12.84$ & $4.69 * *$ \\
\hline Happiness & $8.29+/-1.70$ & $6.76+/-2.27$ & $4.53 * *$ \\
\hline Self-esteem & $32.90+/-4.57$ & $28.59+/-5.83$ & $4.86 * *$ \\
\hline Positive Affect & $4.08+/-1.18$ & $2.51+/-1.56$ & $6.73 * *$ \\
\hline Negative affect & $1.77+/-1.46$ & $2.36+/-1.59$ & $2.15 *$ \\
\hline QOLIE-10 & $18.60+/-5.58$ & $27.75+/-8.22$ & $7.88 * *$ \\
\hline
\end{tabular}

CES-D=Center for Epidemiologic Studies Depression Scale; QOLIE-10=Quality of Life in

Epilepsy 10 -item Scale; $* \mathrm{p} \leq 0.05 ; * * \mathrm{p} \leq 0.01$

including the risk of injury and adverse effects of medications, understandably interfering with lifestyles, activities, and interests. It introduces a number of psychosocial challenges and adaptive demands, threatening QOL. Although these factors are implicit in the literature concerning the psychosocial impact of epilepsy, $3,48,49$ this study was the first to compare the impact of seizure control on illness intrusiveness and QOL in epilepsy. The results are consistent with earlier studies that showed that illness intrusiveness is associated with decreased QOL in different patient populations with other chronic conditions, such as end-stage renal disease, multiple sclerosis, rheumatoid arthritis, breast cancer, systemic lupus erythematosus, and various psychiatric disorders. ${ }^{21-29}$

Conceptualized as a facet of the chronic disease experience that is common across conditions, illness intrusiveness is viewed as a mediating variable intervening between the objective circumstances of disease and treatment on the one hand, and subjective well-being or HRQOL on the other. ${ }^{22}$ The illness intrusiveness model holds that QOL is compromised to the extent that disease and treatment factors interfere with valued activities and interests, reducing the availability of rewarding experiences and personal control. ${ }^{22}$ The illness intrusiveness framework appears valid in epilepsy, ${ }^{34}$ as it has been in other chronic conditions.

Illness intrusiveness can be decreased either by reducing the burden of disease and treatment factors or by moderating contributory psychosocial (e.g., cultural stigma) factors. ${ }^{21}$ From the results of this study it can be seen that in epilepsy medical or surgical interventions resulting in seizure freedom (i.e., eradication of disease burden) are significantly associated with lower levels of illness intrusiveness. Seizure freedom was also associated with lower rates of depression, as well as benefits in terms of perceived personal control, happiness, self-esteem, positive affect and HRQOL. The HRQOL findings are consistent with previous reports documenting the benefits of seizure freedom in patients with epilepsy. ${ }^{6-9}$ The validity of this interpretation is supported by the fact that the observed benefits of seizure freedom were evident for all of the psychosocial and QOL measures we examined.

Drawing from experience with other chronic conditions, it might be possible to decrease illness intrusiveness in patients with epilepsy through interventions aimed at improving psychosocial factors (e.g., eradicating cultural stigma, or improving self-concept or disease-related knowledge through psychotherapy $^{50}$ or psychoeducation ${ }^{51}$ ), interventions that would specifically target the illness intrusiveness stressor with the aim of decreasing its negative impact upon QOL (e.g., behavioral self-management programs ${ }^{52}$ ). Psychosocial interventions might be especially beneficial for medically refractory epilepsy patients who are not candidates for surgical treatment. In this regard, we plan to undertake future studies that include such psychosocial interventions specifically targeting illness intrusiveness.

Although the illness intrusiveness framework has been validated repeatedly and in various conditions, it must be acknowledged that a certain degree of overlap between illness intrusiveness and HRQOL is to be expected simply on the basis of the types of items explored in the respective questionnaires. This is more of a concern for instruments such as the QOLIE or the SF- $36,{ }^{53}$ because they include items that tap interference with roles and activities, than it is for measures of subjective wellbeing, such as measures of depression, happiness, or self-esteem because these tap independent concepts. With respect to depression, the situation is potentially more complicated in epilepsy than other chronic conditions given the possibility of a direct biological link between epilepsy and depression, although the evidence supporting this biological association is admittedly equivocal ${ }^{54}$ Future work will need to address these issues.

In this study group, approximately $62 \%$ of the post-surgical patients reported being seizure free. These results are consistent 
with previous studies, substantiating the representativeness of the current research sample with respect to the post surgical patients. For example, Brodie and Leach ${ }^{55}$ reported $60 \%$ to $70 \%$ seizure freedom following temporal lobectomy and Wiebe and colleagues ${ }^{8}$ reported $58 \%$ seizure freedom one year post-surgery. However, seizure freedom in the pharmacologically treated patients was only $15 \%$, lower than the typically reported $60 \%$ to $70 \%$ seizure freedom rate in the epilepsy population as a whole, which is almost certainly a reflection of the overrepresentation of patients with medically-refractory epilepsy at a tertiary referral centre.

Despite the limitations of small sample size and reliance on self-report questionnaires, the present results provide additional support that the most important benefits of increased QOL (and of decreased illness intrusiveness) in epilepsy occur when treatment leads to complete seizure control. It would appear that illness intrusiveness might be reduced by either of the treatment modalities we examined (i.e., pharmacological or surgical) so long as improved seizure control is the result. Every effort should be made by health care providers to strive for a seizure free outcome in patients with epilepsy, to reduce illness intrusiveness and improve QOL.

\section{REFERENCES}

1. Dodrill CB, Batzel LW, Queisser HR, Temkin NR. An objective method for the assessment of psychological and social problems among epileptics. Epilepsia. 1980; 21: 123-35.

2. Jacoby A, Baker GA, Steen N, Potts P, Chadwick DW. The clinical course of epilepsy and its psychosocial correlates: findings from a UK community study. Epilepsia. 1996; 37: 148-61.

3. Hermann BP, Whitman S, Wyler AR, Antin MT, Vanderzwagg R. Psychological predictors of psychopathology in epilepsy. Br J Psychiatry. 1990; 156: 98-105.

4. Baker GA, Jacoby A, Chadwick DW. The associations of psychopathology in epilepsy: a community study. Epilepsy Res. 1996; 25: 29-39.

5. Gilliam F. Optimizing health outcomes in active epilepsy. Neurology. 2002; 58 Suppl 5: S9-19.

6. Vickrey BG, Hays RD, Engel J Jr, Spritzer K, Rogers WH, Rausch $\mathrm{R}$, et al. Outcome assessment for epilepsy surgery: the impact of measuring health-related quality of life. Ann Neurol. 1993; 37: $158-66$.

7. Vickrey BG, Hays RD, Rausch R, Engel J Jr, Visscher BR, Ary CM, et al. Outcomes in 248 patients who had diagnostic evaluations for epilepsy surgery. Lancet. 1995; 346: 1445-9.

8. Wiebe S, Blume W, Girvin JP, Eliasziw M. A randomized, controlled trial of surgery for temporal-lobe epilepsy. New Eng J Med. 2001; 345: 311-18.

9. Leidy NK, Elixhauser A, Vickrey B, Means E, Willian MK. Seizure frequency and the health-related quality of life of adults with epilepsy. Neurology. 1999; 53: 162-6.

10. Chadwick D. Better comparisons of antiepileptic drugs: what measures of efficacy? Pharm World Sci. 1997; 19: 214-6.

11. Birbeck GL, Hays RD, Cui X, Vickrey B. Seizure reduction and quality of life improvements in people with epilepsy. Epilepsia. 2002; 43: 535-8.

12. Engel J Jr, Van Ness PC, Rasmussen TB, Ojemann LM. Outcome with respect to epileptic seizures. In: Engel J Jr, editor. Surgical treatment of epilepsies. New York: Raven Press; 1993. p. 609-21.

13. Spencer DD, Inserni J. Temporal lobectomy. In: Luders HO, editor. Epilepsy surgery. New York: Raven Press; 1991. p. 533-45.

14. Taylor DC, Falconer MA. Clinical, socioeconomic, and psychological changes after temporal lobectomy for epilepsy. Br J Psychiatry. 1968; 114: 1247-61.

15. McLachlan RS. The Canadian epilepsy database and registry. Can J Neurol Sci. 1998; 25 Suppl 4: S27-31.
16. Dodrill CB, Batzel LW, Fraser R. Psychosocial changes after surgery for epilepsy. In: Luders HO, editor. Epilepsy surgery. New York: Raven Press; 1991. p. 661-7.

17. Guldvog B, Loyning Y, Hauglie-Hassen E, Flood S, Bjornaes H. Surgical versus medical treatment for epilepsy. Outcome related to survival, seizures, and neurologic deficit. Epilepsia. 1991; 32: 375-88.

18. Rose KJ, Derry PA, McLachlan RS. Patient expectations and postoperative depression, anxiety and psychosocial adjustment after temporal lobectomy: a prospective study. Int J Behav Med. 1997; 2: 27-40.

19. Wass CT, Rajala MM, Hughes JM, Sharbrough FW, Offord MS, Rademacher DM, et al. Long-term follow-up of patients treated surgically for medically intractable epilepsy: results in 291 patients treated at Mayo Clinic Rochester between July 1972 and March 1985. Mayo Clinic Proc. 1996; 71: 1105-13.

20. Bishop M, Allen C. The impact of epilepsy on quality of life: a qualitative analysis. Epilepsy Behav. 2003; 4: 226-33.

21. Devins GM, Binik YM, Hutchinson TA, Hollomby DJ, Barre PE, Guttmann RD. The emotional impact of end-stage renal disease: importance of patients' perceptions of intrusiveness and control. Int J Psychiatry Med. 1983; 13: 327-43.

22. Devins GM. Illness intrusiveness and the psychosocial impact of lifestyle disruptions in chronic life-threatening disease. Adv Renal Replace Ther. 1994; 1: 251-63.

23. Devins GM, Edworthy SM, Seland TP, Klein GM, Paul LC, Mandin H. Differences in illness intrusiveness across rheumatoid arthritis, end-stage renal disease, and multiple sclerosis. J Nerv Ment Dis. 1993; 181: 377-81.

24. Devins GM, Edworthy SM, Guthrie NG, Martin L. Illness intrusiveness in rheumatoid arthritis: differential impact on depressive symptoms over the adult lifespan. J Rheumatol. 1992; 19: 709-15.

25. Devins GM, Edworthy SM. Illness intrusiveness explains racerelated quality-of-life differences among women with systemic lupus eythematosus. Lupus. 2000; 9: 534-41.

26. Devins GM, Armstrong SJ, Mandin H, Paul LC, Hons RB, Burgess $\mathrm{ED}$, et al. Recurrent pain, illness intrusiveness and quality of life in end-stage renal disease. Pain. 1990; 42: 279-85.

27. Devins GM, Beanlands H, Mandin H, Paul LC. Psychosocial impact of illness intrusiveness moderated by self-concept and age in end-stage renal disease. Health Psychol. 1997; 16: 529-38.

28. Bloom JR, Stewart SL, Johnston M, Banks P. Intrusiveness of illness and quality of life in young women with breast cancer. Psychooncology. 1998; 7: 89-100.

29. Antony MM, Roth D, Swinson RP, Huta V, Devins GM. Illness intrusiveness in individuals with panic disorder, obsessive compulsive disorder or social phobia. J Nerv Ment Dis. 1998; 186: $311-5$

30. Robb JC, Cooke RG, Devins GM, Young LT, Joffe RT. Quality of life and lifestyle disruption in euthymic bipolar disorder. J Psychiatr Res. 1997; 31: 509-17.

31. Binik YM, Devins GM. Transplant failure does not compromise quality of life in end-stage renal disease. Int J Psychiatry Med. 1986; 16: 281-92.

32. Littlefield C, Abbey S, Fiducia D, Cardella C, Greig P, Levy G, et al. Quality of life following transplantation of the heart, liver, and lungs. Gen Hosp Psychiatry. 1996; 18 Suppl 6: S36-47.

33. Devins GM, Flanagan M, Morehouse R, Moscovitch A, Plamondon J, Reinish L, et al. Differential illness intrusiveness associated with sleep-promoting medications. Eur Psychiatry. 1995; 10 Suppl: S153-9.

34. Poochikian-Sarkissian S. Illness intrusiveness, quality of life and self-concept in epilepsy. Ph.D. Thesis, Toronto $(\mathrm{ON})$ : University of Toronto; 2005.

35. Gilliam F, Kuzniecky R, Meador K. Patient-oriented outcome assessment after temporal lobectomy for refractory epilepsy. Neurology. 1999; 53: 687-94.

36. Lehrner J, Kalchmay R, Serles W. Health-related quality of life, activity of daily living and depressive mood disorder intemporal lobe epilepsy patients. Seizure. 1999; 8: 88-92. 
37. SPSS 7.0 Statistical algorithms [Computer Program Manual]. Chicago, (IL); 1996.

38. Cohen J, Cohen P. Applied multiple regression/correlation analysis for the behavioral sciences, 3rd ed. Mahwah: Lawrence Erlbaum Associates; 2003.

39. Flanagan JC. A research approach to improving our quality of life. Am J Psychol. 1978; 33: 138-47.

40. McDowell J, Newell C. Measuring health: a guide to rating scales and questionnaires. Oxford University Press: New York; 1996.

41. Bradburn NM. The structure of psychological well-being, 1st ed. Aldine: Chicago; 1969.

42. Atkinson TA. The stability and validity of quality of life measures. Soc Indic Res. 1982; 10: 113-32.

43. Rosenberg M. Conceiving the self. New York: Basic Books; 1979.

44. Robinson JP, Shaver PR, Wrightsman LS. Measures of personality and psychological attitudes. San Diego: Academic Press; 1991.

45. Radloff LS. The CES-D scale: a self-report depression scale for research in the general population. Appl Psych Measures. 1977; 3: 385-401.

46. Cramer JA, Perrine K, Devinsky O, Meador K. A brief questionnaire screen for quality of life in epilepsy: the QOLIE10. Epilepsia. 1998; 37: 577-87.

47. Devinsky O, Vickrey BG, Cramer J, Parrine K, Hermann B, Meador $\mathrm{K}$, et al. Development of the quality of life in epilepsy inventory. Epilepsia. 1995; 36: 1089-104.
48. Dodrill CB, Breyer DN, Diamond MB, Dubinsky BL, Geary BB. Psychosocial problems among adults with epilepsy. Epilepsia. 1984; 25: 168-75.

49. Hermann BP, Whitman S. Behavioural and personality correlates of epilepsy: a review, methodological critique, and conceptual model. Psychol Bull. 1984; 95: 451-97.

50. Edworthy SM, Dobkin PL, Clarke AE, Da Costa D, Dritsa M, Fortin PR, et al. Group psychotherapy reduces illness intrusiveness in systemic lupus erythematosus. J Rheumatol. 2003; 30: 1011-6.

51. Devins GM, Mendelssohn DC, Barre PE, Binik YM. Predialysis psychoeducational intervention and coping styles influence time to dialysis in chronic kidney disease. Am J Kidney Dis. 2003; 42: 693-703.

52. Bodenheimer T, Lorig K, Holman H, Grumbach K. Patient selfmanagement of chronic disease in primary care. JAMA. 2002; 288: 2469-75.

53. Ware JEJ, Sherbourne CD. The MOS 36-item short-form health survey (SF-36) Conceptual framework and item selection. Med Care. 1992; 30: 473-83.

54. Kanner AM, Balabanov A. Depression in epilepsy: how closely related are these two disorders? Neurology. 2002; 58 Suppl 5: S27-39.

55. Brodie MJ, Leach JP. Success or failure with antiepileptic drug therapy: beyond empiricism? Neurology. 2003; 60: 162-3. 